\title{
Identification of a novel Dlg2 isoform differentially expressed in IFN $\beta$-producing plasmacytoid dendritic cells
}

\author{
Shafaqat Ali ${ }^{1,2 \dagger}$, Alexander Hoven ${ }^{1 \dagger}$, Regine J. Dress ${ }^{1,3 \dagger}$, Heiner Schaal ${ }^{4,5}$, Judith Alferink ${ }^{2,6}$ and Stefanie Scheu ${ }^{1 *}$
}

\begin{abstract}
Background: The murine discs large homolog 2 (DLG2; post synaptic density 93 (PSD-93); Chapsyn-110) is a member of the membrane-associated guanylate kinase (MAGUK) protein family involved in receptor assembly and associated with signaling enzymes on cell membranes. In neurons, DLG2 protein isoforms derived from alternatively spliced transcripts have been described to bind to NMDA ( $\mathrm{N}$-methyl-aspartate) receptors and $\mathrm{K}$ channels and to mediate clustering of these channels in the postsynaptic membrane. In myeloid cells of the immune system, such as dendritic cells (DCs), a lack of data exists on the expression or function of DLG2. In CDNA microarray transcriptome analyses, we found Dlg2 highly expressed in a subpopulation of plasmacytoid DCs (pDCs) stimulated to produce type I interferons (IFNs) such as IFNß.

Results: Using RACE- and RT-PCR as well as immunoprecipitation followed by Western blotting we characterised the differential expression of the Dlg2 splice variants in IFNß-producing pDCs. Besides Dlg2 $\gamma$ this cell population expressed a novel short Dlg2n transcript we termed Dlg2n3. Our expression data were integrated into information from genome databases to obtain a novel and comprehensive overview of the mouse Dlg2 gene architecture. To elucidate the intracellular localisation pattern of protein isoforms, ectopical expression analysis of fluorescently tagged DLG2 splice variants was performed. Here we found an enrichment of the larger isoform DLG2a1 at the plasma membrane while

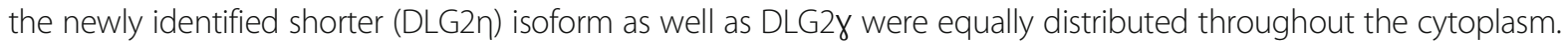
Additionally, DLG2 $\eta$ was also found in the nucleus. Analysis of Dlg2-knockout mice previously generated by deleting exon 9 surprisingly revealed that the protein for the novel DLG2 $\eta$ isoform was still expressed in the brain and in bone marrow-derived pDCs from mice carrying the homozygous deletion $\left(D \lg 2^{\triangle E 9 / \triangle E 9}\right)$.
\end{abstract}

Conclusion: We describe a novel splice variant of the mouse Dlg2 gene termed Dlg2 $\eta$ and define the differential expression pattern of DLG2 isoforms in IFN $\beta$-producing pDCs. The presence of DLG2n protein in the CNS of D/g $2^{\Delta E g / \Delta E 9}$ mice might influence the phenotype of these mice and has to be taken into account in the interpretation of results regarding the functional role of DLG2 in neuronal postsynaptic membranes.

Keywords: Dlg2, PSD-93, IFNß, Plasmacytoid dendritic cells, Isoforms

\section{Background}

Discs large homolog 2 (DLG2), also known as post synaptic density 93 (PSD-93) or Chapsyn-110, is a member of the membrane-associated guanylate kinase family of proteins (MAGUKs). Functionally, these proteins are best described as postsynaptic scaffold proteins binding neurotransmitter receptors and enzymes involved in the

\footnotetext{
* Correspondence: stefanie.scheu@uni-duesseldorf.de

${ }^{\dagger}$ Equal contributors

'Institute of Medical Microbiology and Hospital Hygiene, Heinrich, Heine University of Düsseldorf, Universitätsstraße 1, D-40225 Düsseldorf, Germany

Full list of author information is available at the end of the article
}

formation of signaling complexes in the postsynaptic density in neurons [1-5]. More specifically, MAGUKs control the trafficking of $N$-Methyl-D-aspartate (NMDA) and $\alpha$-amino-3-hydroxy-5-methyl-4-isoxazole propionic acid (AMPA) type glutamate receptors to the synapse and thus excitatory synaptic transmission [2, 5-7]. In mammals five homologues of $D \lg 2$ are found - $D \lg 1$ (SAP-97, hDLG), Dlg3 (SAP-102), Dlg4 (PSD-95, SAP90), Dlg5, and Dlg6 (Mpp4) [3-5, 7-11]. The respective contribution of the different $\mathrm{Dlg}$ homologues to synapse formation and function is still under debate. 
Gene mutations in human DLGs have been shown to be causative for a spectrum of psychiatric disorders [3, 12]. Most prominently among these, mutations, copy number variations, or altered expression levels in four DLG homologues (Dlg1, Dlg2, Dlg3 and Dlg4) have been implicated in the development of schizophrenia [13-19]. Further, DLG3 mutations result in nonsyndromic X-linked mental retardation [20], while forms of autism are associated with mutations in Neuroligins, binding partners of DLG4 [21]. Recently, DLG2 has been associated with neurodevelopmental disorders in general and also with the pathogenesis of migraine [22, 23]. Important mechanistic insights have been gained by the analyses of mouse models with selective or combined deficiencies in $D l g$ homologues. Here, mutations in $D \lg 2$ and $D \lg 4$ lead to hypersocial behaviour and alterations in complex cognitive processes, while simple associative learning was impaired in Dlg4-deficient mice $[8,24]$.

All DLG homologues share a characteristic structure of protein-protein interaction domains. A variable $\mathrm{N}$ terminal domain is followed by three PSD-95/discs large/ zona occludens-1 (PDZ) domains and a src-homology 3 (SH3) domain that is linked to a guanylate kinase (GK) like domain $[4,5,25,26]$. DLG6 here represents an exception in containing only one PDZ domain. PDZ domains typically bind to short amino acid motifs at the C-termini or internal $\beta$-finger motifs of interacting proteins such as receptors, ion channels, or enzymes [5, 27-29]. The SH3GK domains are speculated to mediate oligomerization of DLGs [2, 5, 26].

Multiple isoforms exist for all six DLG homologues. Their transcripts are generated by using alternative transcription start sites and alternative splicing of exons. DLG isoforms exhibit differences in neuronal trafficking and fulfil specific roles in synaptic functioning [26, 30]. Of the six DLG homologues, DLG2 exhibits the highest number of variations in its $\mathrm{N}$-terminal domains [25, 31]. The six N-termini of DLG2 so far described comprise two palmitoylated isoforms ( $\alpha 1$ and $\alpha 2$ ), one L27 domain containing isoform $(\beta)$, and three additional isoforms termed $\gamma, \delta$, and $\varepsilon[23,25,31]$.

In addition to the different $\mathrm{N}$-termini, isoform variability of DLG2 in neurons is achieved by alternative splicing of exons coding for the linker region between the $\mathrm{SH} 3$ and the GK domain $[25,32]$. This linker region might facilitate binding to different interaction partners depending on the splice variant expressed [26, 32]. Similarly, for DLG1, a specific interaction in this region with the actin/spectrin binding protein, protein 4.1, has been described that targets DLG1 to neuronal spines [33].

Knowledge of the expression pattern and function of splice variants of $D \lg 2$ outside the nervous system is very limited. Within the immune system only two broad scale transcription profiling approaches indicate significant expression levels of $D \lg 2$ in mast cells and splenic red pulp macrophages, respectively [34, 35]. So far, nothing is known about the expression or function of DLG2 in other cells of the immune system. In a transcription profiling approach we found $D \lg 2$ as highly expressed in pDCs that produce IFN $\beta$ [36]. The pDC subset of dendritic cells is considered to be specialized in the rapid production of high amounts of antiviral type I IFNs after activation but has a rather limited activity in antigen presentation and $\mathrm{T}$ cell priming as compared to conventional DCs $[37,38]$. Recently we could show, using our IFN $\beta$ / YFP $\left(I F N \beta^{\text {mob/mob }}\right)$ reporter mice, that only a small subset of these pDCs is responsible for the initial expression of type I IFNs after systemic activation of the pattern recognition receptor TLR9. The type I IFN-producing $\mathrm{pDCs}$ are equipped with a specific gene signature enabling them to control leukocyte recruitment and to coordinate early cellular immune responses [36]. Interestingly, Dlg2 was found to be the transcript with the highest differential expression in these type I IFN-producing pDCs.

In this study, we present a revised annotation of the mouse genomic $D l g 2$ locus and define a cell specific splicing pattern for $D \lg 2$ in murine pDCs. Additional to the previously described neuronal splice forms, we found a novel, shorter splice variant termed $D \lg 2 \eta 3$. This isoform is specifically expressed in pDCs after stimulation with Toll like receptor 9 (TLR9) ligands. Further, we detected that protein expression of DLG2 $\eta$ was retained in the earlier published $D \lg 2^{\Delta E 9 / \Delta E 9}$ mouse line [39] with unknown but possible functional implications for the phenotype of these mice.

\section{Methods}

Mice and in vivo treatments

$D \lg 2^{\Delta E 9 / \triangle E 9}$ [39] mice were a kind gift of Seth G. N. Grant (Edinburgh University, Edinburgh, UK). Bicistronic Interferon $\beta$ /YFP reporter knock-in mice (mob: messenger of IFN beta; IFN $\beta^{\text {mob/mob }}$ ) have been described previously [40]. IFN $\beta^{\text {mob/mob }}, D \lg 2^{\triangle E 9 / \triangle E 9}$ mice, and their wild type (WT) littermates are on C57BL/6 N background and were kept under pathogen-free conditions. The mice were euthanized by cervical dislocation. The experiments were approved by the government of North-Rhine Westphalia. Where indicated, mice were injected i.v. with $10 \mu \mathrm{g}$ CpG 1668 (TIB MOLBIOL) complexed to DOTAP (Roche) for $6 \mathrm{~h}$, or as indicated.

\section{Generation and stimulation of bone marrow-derived pDCs}

Bone marrow (BM)-derived FMS-like tyrosine kinase 3 ligand (Flt3L)-cultured pDCs were generated as previously described [40]. Cells were stimulated with $1 \mu \mathrm{M}$ CpG 2216 (TIB MOLBIOL) complexed to DOTAP (Roche) for $6 \mathrm{~h}$, or as indicated. 


\section{Flow cytometry and cell sorting}

Cells were analysed on a FACSCanto II (BD). DAPI was added for dead cell discrimination. FACS sorting was performed on a FACSAria (BD) after MACS (Miltenyi Biotec) depletion of $\mathrm{CD} 3 \varepsilon / \mathrm{CD} 19^{+}$cells. Monoclonal antibodies against B220, CD3e, CD11b, CD11c, CD19, CD27, CD86, and CD16/32 were purchased from BD, mPDCA-1 was purchased from BioLegend.

\section{Gene expression analyses}

RNA was isolated from FACS-sorted in vivo differentiated or BM-derived Flt3L cultured pDCs using the NucleoSpin RNA Isolation Kit (MACHEREY-NAGEL). Expression of $D l g 2$ and Ifnb was analysed in IFN $\beta / \mathrm{YFP}^{+}$and IFN $\beta / \mathrm{YFP}^{-}$ pDCs using quantitative RT-PCR (qRT-PCR). qRT-PCR was performed using the TaqMan Master Kit with the Universal Probe Library Set (Roche) or the MESA GREEN qPCR MasterMix Plus (Eurogentec) on an iQ5 or CFX96 (Bio-Rad). The primer sequences used for qRT-PCR are as follows: mDlg2-fwd AAACGCTCCCTGTATGTCAGA, mDlg2-rev CCCCATCTAGTGTGACCCTTC, Ifnb-fwd C AGGCAACCTTTAAGCATCAG, Ifnb-rev CCTTTGAC CTTTCAAATGCAG, $\beta$-actin-fwd TGACAGGATGCAG AAGGA, and $\beta$-actin-rev CGCTCAGGAGCAATG.

\section{Mammalian cell culture and transient transfection}

NIH3T3 cells were purchased from ATCC. The HEK293 derived cell line 293FT was purchased from Thermo Scientfic. Both cell lines were maintained in Dulbecco's modified Eagle's medium (DMEM, Gibco) containing $10 \%$ heat inactivated fetal bovine serum (FBS; Pan Biotech) and $2 \mathrm{mM}$ L-glutamine (Biochrom) at $10 \% \mathrm{CO}_{2}$. Cells were transiently transfected with plasmids as indicated in figure legends by a slightly modified polyethylenimine (PEI; Aldrich) transfection method [41].

\section{Immunoprecipitation and western blotting}

First, BM-derived Flt3L cultured pDCs were generated from $D \lg 2^{\triangle E 9 / \Delta E 9}$ mice or WT littermates as described above. After 7 days of differentiation in Flt3L containing medium, $12 \times 10^{7}$ BM-derived Flt3L cultured DCs were either left untreated or stimulated with CpG 2216 complexed to DOTAP for $16 \mathrm{~h}$. At the end of the stimulation time cells were washed and lysed with RIPA lysis buffer for $30 \mathrm{~min}$ at $4{ }^{\circ} \mathrm{C}$. Insoluble fractions were removed before the supernatant was incubated with anti-DLG2 (Abcam) antibody coupled to protein $\mathrm{G}$ agarose beads (Sigma-Aldrich) for $16 \mathrm{~h}$ at $4{ }^{\circ} \mathrm{C}$ with gentle rotation. Washed beads were resuspended in Laemmli sample buffer and heated to $95{ }^{\circ} \mathrm{C}$ for $10 \mathrm{~min}$. In parallel, transiently transfected HEK293 cells were washed with PBS and lysed as described above. After SDS/PAGE, DLG2 was detected in a Western blot with mouse anti-DLG2 (Millipore) or rabbit anti-DLG2 (Abcam) antibodies.

\section{Expression plasmids}

$p D \lg 2 \alpha-E G F P, p D \lg 2 \gamma$-EGFP and $p D \lg 2 \eta$-EGFP encode the murine DLG2 $\alpha$, DLG2 $\gamma$, and DLG2 $\eta$ isoforms, respectively, C-terminally fused to EGFP. The respective transcription unit in the $p E G F P-N 1$ vector (Clontech) is under control of the CMV promoter. $D \lg 2 \alpha, \gamma$, and $\eta$ isoforms were amplified by PCR using Dlg2 $\alpha M 1$ s_KEco (TCGGAATTCGCCACCATGTTCTTTGCATGTTATT

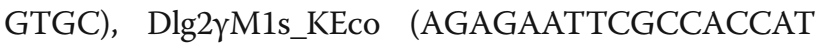
GTTACCGACTTTCGATATGC), Dlg2ๆM1s_KEco (TGA GAATTCGCCACCATGATGAACCACAGCATGAGC) as sense primer respectively and Dlg2-stopas_Bam (TGCGGATCCAACTTCTCCTTTGAGGGAATC) as antisense primer. Amplified PCR products were ligated into the $p E G F P-N 1$ vector (Clontech) at the EcoRI and $B a m H I$ sites. The $p I F N \beta$-Luc reporter plasmid encodes the firefly luciferase under the control of the Ifnb minimal promoter and was used for the Ifn $b$ reporter gene assays. $p R L-$ $C M V$ (Promega) encodes renila luciferase under the control of CMV promoter. $p R L-C M V$ was used as an internal transfection control in reporter gene assays. pFlag-IRF7 encodes an $\mathrm{N}$-terminally Flag tagged interferon regulatory factor 7 (IRF7). phTBK1-Flag-His encodes a C-terminally Flag and His tagged human TANK binding kinase 1 (TBK1). $p$ CI-TPI-WT-4H encodes human triosephosphate isomerase 1 (TPI1) under CMV promoter [42]. Primers and cloning details are available on request.

\section{Reporter gene assay}

For IRF7-dependent reporter gene assays, $1.25 \times 10^{5}$ NIH3T3 cells were cotransfected with $50 \mathrm{ng}$ pIFN $\beta-L u c$, 5 ng $p R L-C M V$, 10 ng pFlag-IRF7, 40 ng phTBK1-FlagHis and 0, 70, 140, or $280 \mathrm{ng} D l g 2$ isoforms or TPI1 encoding plasmids in 24-well plates. The total amount of plasmid DNA was always maintained by adding empty vector. $20 \mathrm{~h}$ after transfection, cells were lysed with $100 \mu \mathrm{l}$ passive lysis buffer (Promega). Luciferase activity was measured using the dual luciferase assay system (Promega) as described earlier [43].

\section{Immunostaining and microscopy}

BM-derived Flt3L cultured pDCs were either kept untreated or stimulated with $1 \mu \mathrm{M}$ CpG 2216 for $24 \mathrm{~h}$. Cells were transferred on coverslips by centrifugation. NIH3T3 cells were cultured and transfected on cover slips. Paraformaldehyde fixed cells were stained for different markers as shown in the figures. DAPI was used as nuclear marker. Abs against $\mathrm{Na} / \mathrm{K}$ ATPase and GFP/ YFP were purchased from Abcam, CD16/32, DLG2 and mPDCA-1 were purchased from BD, Millipore, and Miltenyi Biotec, respectively. Images were taken on a LSM 780 (Zeiss) confocal microscope and processed using Adobe Photoshop and ZEN 2011/12 software. 
RACE PCR and isotype specific PCR

BM-derived Flt3L cultured pDCs were generated from IFN $\beta^{\text {mob/mob }}$ mice. Cells were stimulated with $1 \mu \mathrm{M}$ CpG 2216 for $6 \mathrm{~h}$ and IFN $\beta / \mathrm{YFP}^{+}$and IFN $\beta / \mathrm{YFP}^{-}$pDCs were FACS sorted. Rapid amplification of cDNA ends (RACE) was performed using SMARTer RACE 5'/3' kit (Takara Clontech) and $m D l g 2$ 5RACE GSP1 (GATTACGC CAAGCTTCCTCTGTTTCCTTCATGGCTTCAC) or $m D l g 2$ 5RACE GSP2 (GATTACGCCAAGCTTTGTCG TTGTCAGAGGTGCAGTAGC) primers. Amplified PCR products were cloned using In-Fusion HD cloning kit (Takara Clontech). Primers used for isotype specific RTPCR analysis of $D \lg 2$ isoforms are given in Table 1.

\section{Statistical analysis}

Data are shown as individual values with mean \pm SEM. Differences between two groups were tested using t-test. A $p$-value $<0.05$ was considered as significant. Multiple comparisons were performed with One-way ANOVA followed Bonferroni's Multiple comparison Test or Twoway ANOVA followed by Bonferroni posttests. GraphPad Prism 5.0 was used to perform statistical analyses and to prepare graphs.

Table 1 Primer used for isotype specific RT-PCR

\begin{tabular}{|c|c|c|}
\hline Name & Exon & Sequences $\left(5^{\prime}-3^{\prime}\right)$ \\
\hline Dlg2a1 fwd & a1 & CTGAGCTCTCACTCAGTGCCTTC \\
\hline Dlg2a2 fwd & $a 2$ & AGCTGCCGCTCTGTCTAGGCTG \\
\hline $\mathrm{Dlg} 2 \delta \mathrm{fwd}$ & $\delta$ & GGGAGGAAGCCTITCTATGCAG \\
\hline Dlg2rev & 11 & CGGTGGCCCATAAGGATCAGT \\
\hline$D \lg 2 a 0 / \beta$ fwd & 4 & AAGGCAAATGCCCAGCCCAG \\
\hline Dlg2a0/ $\beta$ rev & 9 & TAGAGCCGGCTTCCTTGAG \\
\hline Dlg2 2 fwd & $\gamma$ & GTGAAGAAGCTATGCAACACGCGT \\
\hline Dlg2y rev & 14 & CGAGTTGCAGTACTGTGCTGG \\
\hline $\mathrm{D} \lg 2 \varepsilon$ fwd & $\varepsilon$ & GCCAACTGGATGTGTGTGAGCCG \\
\hline $\mathrm{Dlg} 2 \varepsilon \mathrm{rev}$ & 9 & CACAACAGTCTCCAATATGGGTCGC \\
\hline Dlg2ろ1 fwd & $\zeta 1$ & AGCTGGCTGTGTTTCCAGTGCC \\
\hline Dlg2 2 fwd & $\zeta 2$ & TCCCCAGAGCCCATATAGAGCCA \\
\hline Dlg2n1 fwd & $\eta 1$ & ACACAACAGCCCCCAAACCAC \\
\hline Dlg2n2 fwd & $\eta 2$ & ACCGGACAGGAGACAGGAGA \\
\hline Dlg2n rev & 17 & TGACATACAGGGAGCGTITCT \\
\hline Dlg2 E18 fwd & 18 & AGAAGGGTCACACTAGATGG \\
\hline Dlg2 E19 fwd & 19 & GTGGAAAGAAAGGAGCGTG \\
\hline Dlg2 E20 fwd & 20 & CCATTCTACAAGAACAAGGAGC \\
\hline Dlg2 E21 fwd & 21 & ATTAGGTGACGACGGTTATGG \\
\hline Dlg2 E20 rev & 20 & ATCACTGGTTTCCTGCTCAC \\
\hline Dlg2 E21 rev & 21 & GAGTCTITGTTCCATAACCGTC \\
\hline Dlg2 E22 rev & 22 & AGCTACTTTCGCTATCGCTG \\
\hline Dlg2 E23 rev & 23 & GCCTCGTGACAGGTTCATAG \\
\hline
\end{tabular}

\section{Results}

Correlation of DLG2 and IFN $\beta$ expression in mouse pDCs In our recent microarray based transcriptome analyses $D l g 2$ was found to be differentially expressed in IFN $\beta$ producing pDCs [36]. To verify our previously generated microarray data by an independent method we first performed quantitative analysis of mouse Dlg2 mRNA expression on ex vivo FACS sorted splenic or in vitro Flt3L cultured BM-derived pDCs (Fig. 1a, b). To induce and to track IFN $\beta$ expression in $\mathrm{pDCs}$, IFN $\beta /$ YFP reporter mice $\left(I F N \beta^{\text {mob/mob }}\right)$ were injected i.v. with the TLR9 ligand $\mathrm{CpG}$ and IFN $\beta$-expressing $\mathrm{YFP}^{+}$and IFN $\beta$-nonproducing $\mathrm{YFP}^{-}$splenic pDCs were FACS sorted $6 \mathrm{~h}$ after stimulation. Quantitative RT-PCR analysis showed a higher expression of Ifn $b$ in IFN $\beta / \mathrm{YFP}^{+}$vs. IFN $\beta / \mathrm{YFP}^{-}$ pDCs $(549.7 \pm 144.8$ fold) confirming the purity of the sorted cells as well as the functionality of the IFN $\beta /$ YFP reporter model. For Dlg2, markedly higher mRNA levels

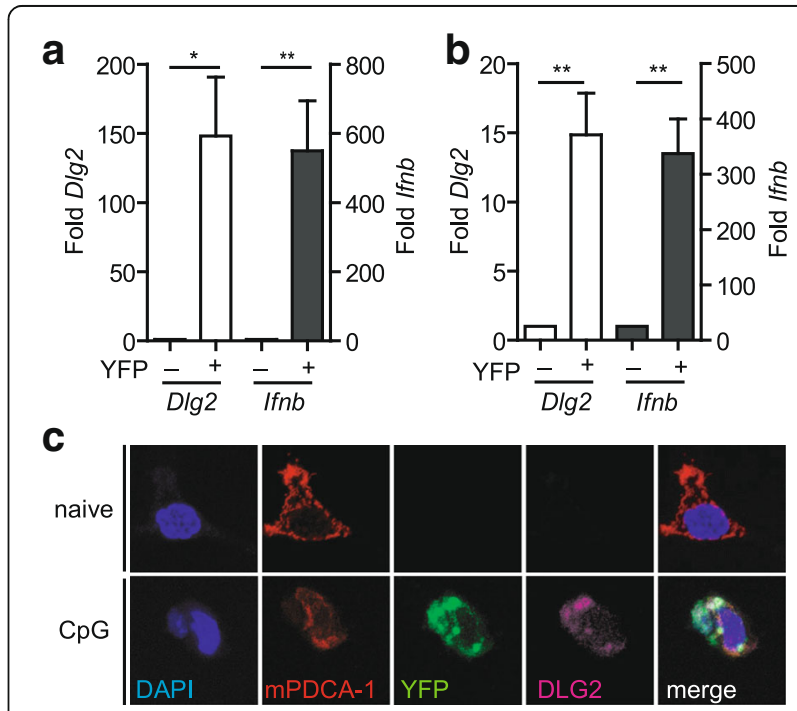

Fig. 1 High expression of DLG2 in IFN $\beta$-producing pDCs. (a) Analysis of Dlg2 expression in splenic PDCs. IFN $\beta /$ YFP $^{+}$and IFN $\beta / Y_{F P}-$ splenic pDCs were ex vivo FACS sorted from IFN $\beta^{\text {mob/mob }}$ mice $6 \mathrm{~h}$ after i.v. injection with CpG. Dlg2 (white bars) and Ifnb (black bars) mRNA expression was analysed by quantitative RT-PCR. (b) Dlg2 expression in in vitro BM-derived $\mathrm{pDCs}$. BM-derived DCs were generated from IFN $\beta$ $\mathrm{mob} / \mathrm{mob}$ mice in Flt3L cultures. IFN $\beta / \mathrm{YFP}^{+}$and IFN $\beta / \mathrm{YFP}^{-}$BM-derived pDCs were FACS sorted $6 \mathrm{~h}$ after stimulation with CpG. Dlg2 (white bars) and Ifnb (black bars) mRNA expression was analysed by quantitative RT-PCR. Data shown in (a) and (b) is fold mRNA quantity in IFN $\beta$ producing $\mathrm{pDC}$ s relative to IFN $\beta$ non-producers. Data shown is mean \pm standard error of mean (SEM) from four independent experiments (each sample is pooled from 12 (a) or 6 (b) mice. Statistical differences between IFN $\beta / \mathrm{YFP}^{+}$and IFN $\beta / \mathrm{YFP}^{-}$were analysed by two tailed, unpaired t test. ns: $P>0.05,{ }^{*}: P<0.05,{ }^{*}: P<0.01,{ }^{* * *}: P<0.001$. (c) Immunofluorescence images of DLG2 expression in BM-derived Flt3L cultured pDCs left untreated (naïve; upper panel) and $24 \mathrm{~h}$ after CpG (CpG; lower panel) stimulation. Cells were stained with antibodies against DLG2 and mPDCA-1 and a YFP-crossreacting antibody against GFP. Data shown is one representative experiment out of three independent experiments with comparable results 
$(148.0 \pm 42.6$ fold $)$ were measured in $\operatorname{IFN} \beta / \mathrm{YFP}^{+}$vs. IFN $\beta / \mathrm{YFP}^{-}$ex vivo sorted $\mathrm{pDCs}$ corroborating our earlier transcriptome data (Fig. 1a). Next, we tested whether $D l g 2$ is also highly expressed in type I IFN-producing pDCs independent of the anatomical splenic environment in vitro. For this, BM-derived Flt3L cultured pDCs were stimulated with $\mathrm{CpG}$ for $6 \mathrm{~h}$ to activate type I IFN production and FACS sorted for IFN $\beta /$ YFP expression. In this in vitro system, as well, elevated Dlg2 mRNA levels $(14.8 \pm 3.0$ fold $)$ correlated well with a higher expression of Ifnb (337 \pm 63.0 fold) in IFN $\beta / \mathrm{YFP}^{+}$as compared to IFN $\beta / \mathrm{YFP}^{-}$pDCs (Fig. 1b). Of note $D \lg 2$ expression was also detectable in conventional DCs (cDCs) albeit to a lesser extent. Also, in cDCs CpG stimulation did not lead to an increase in $D \lg 2$ mRNA levels (Additional file 1).

Similar to pDCs, B cells constitutively express TLR9 [44]. TLR9 stimulation with CpG results in increased CD27 surface expression in a sub-population of B cells which correlates with higher antibody-secretion in these cells [45]. We asked whether in B cells higher CD27 surface levels correlate also with increased $D \lg 2$ expression after $\mathrm{CpG}$ stimulation. Therefore, we analyzed the expression of Dlg2 in CD27-positive versus CD27-negative B cell sub-populations after TLR9 stimulation. Dlg2 expression, however, did not correlate with CD27 expression in these cells and was around 150 fold less as compared to BM-derived IFN $\beta / Y F P$-producing pDCs (Additional file 2). Of note, Ifnb mRNA levels in both B cell subpopulations were also 250 fold lower as compared to the professional type I IFN producers. These data suggest a pDC-specific elevated expression of $D \lg 2$ upon TLR9 activation.

Finally, coexpression of DLG2 and IFN $\beta$ was analysed at protein level in BM-derived Flt3L cultured pDCs left untreated or stimulated for $24 \mathrm{~h}$ with CpG. Here, immunofluorescent staining for DLG2 was detected exclusively in $\mathrm{CpG}$ stimulated pDCs that exhibited a positive signal for IFN $\beta /$ YFP (Fig. 1c). These data indicate that Dlg2 mRNA as well as DLG2 protein is highly differentially expressed in IFN $\beta$-expressing pDCs as compared to $\mathrm{pDCs}$ not producing IFN $\beta$ ex vivo as well as in vitro.

\section{Dlg2 splice variants expressed in IFN $\beta$-expressing pDCs}

Six N-terminal protein variants have been described for mouse DLG2, including two palmitoylated isoforms and an L27 domain containing isoform [25, 31]. Transcripts initiated at alternative promoters are responsible for the expression of these different $\mathrm{N}$-terminal domains. Additionally, alternative splicing leads to variations in the usage of exons coding for the SH3-GK linker region of DLG2 [25]. Here, we generated an updated version of the mouse $D l g 2$ gene architecture by integrating current information available from the ENSEMBL and NCBI genome databases (Fig. 2a and Additional file 3). The terms for the alternative $\mathrm{N}$-terminal protein domains $\alpha$, $\beta, \varepsilon, \delta$, and $\gamma$ were adopted as suggested by Krüger et al. [25]. In contrast to the previously published gene structure [25], we found two additional exons coding for distinct $\mathrm{N}$-terminal L27 containing $\beta$-isoforms. We termed these exons, at the very $5^{\prime}$ end of $D \lg 2, \beta 1$ and $\beta 2$. The $\beta 1$ exon is spliced onto exon 1 or alternatively to the $\beta 2$ exon which then is spliced onto exon 1 (Additional file 3). The first possibility results in a protein translated from the start codon in the $\beta 1$ exon. The second splice variant generates a premature stop codon for translation events initiated from the start codon in the $\beta 1$ exon. Thus, the DLG2 $\beta 2$ protein is produced using the start codon in the $\beta 2$ exon (Fig. 2a). In a sequence available in the database under the annotation XM_006507768 both these exons, $\beta 1$ and $\beta 2$, are combined into a larger single exon retaining the otherwise intronic sequence. From this sequence, also only the DLG2 $\beta 2$ isoform can be translated. Exons 1 to 3 are shared by all L27 containing $\beta$-isoforms. For the palmitoylated $\alpha$-isoforms we found three exons $(\alpha 0, \alpha 1$, and $\alpha 2$ ) coding for distinct $\mathrm{N}$-termini (Fig. 2a and Additional file 3). This is in contrast to previous analyses where only two $\alpha$ exons had been described [25]. The here defined exon $\alpha 0$ is spliced onto exon 4 that is shared by all $\beta$ isoforms whereas both, exon $\alpha 1$ and $\alpha 2$, are spliced directly onto exon 5 which is common for all $\alpha$ - and $\beta$ isoforms. Exon 5 as well as the unique exons coding for the $\mathrm{N}$-termini of the isoforms $\varepsilon$ and $\delta$ can each be spliced onto exon 6. In contrast, the exon coding for the Nterminus of the isoform $\gamma$ is spliced alternatively onto exon 6 or directly onto exon 7. Further analyses of recent database entries revealed the existence of two additional $\mathrm{N}$-terminal domains we termed $\zeta$ and $\eta$ (Fig. 2a and Additional file 3). The two consecutive exons $\zeta a$, which is non-coding, and $\zeta \mathrm{b}$, which contains the translational start codon for the $\mathrm{N}$-terminus of the $\zeta$-isoform, are spliced onto exon 15 . This exon is shared also by the $\alpha-, \beta-, \varepsilon_{-}, \delta$-, and $\gamma$-isoforms. Finally, the open reading frame of the $\eta$ isoform is preceded by either one of the two non-coding exons $\eta 1$ or $\eta 2$ which are spliced onto exon 17 , the most $5^{\prime}$ exon present in all known isoforms of $D \lg 2$. The variable linker sequences between the SH3 and the GK domain are encoded by the alternatively spliced exons 20 to 23 according to our updated gene annotation.

We next defined the expression of the different $\mathrm{N}$ terminal isoforms in pDCs. For this we performed RTPCR analyses on sorted Flt3L cultured BM-derived IFN $\beta / \mathrm{YFP}^{+}$or IFN $\beta / \mathrm{YFP}^{-}$pDCs $6 \mathrm{~h}$ after stimulation with CpG (Fig. 2b). RNA isolated from whole brains of C57BL/6 N mice served as control. While transcripts for all $\alpha-, \beta-, \varepsilon-, \delta-, \gamma_{-}, \zeta-$, and $\eta 1 / 2$-isoforms could be amplified from brain, in pDCs only the $\gamma$-transcripts were detectable. Corroborating our results from quantitative RT-PCR analyses using primers that detect all known 


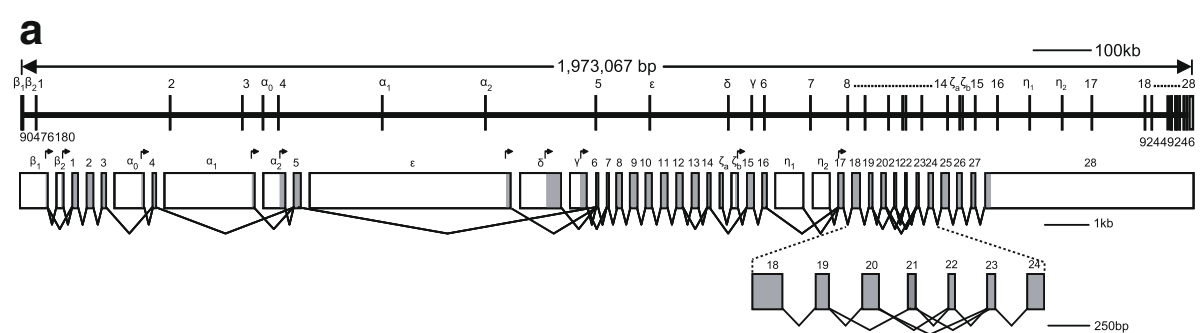

b
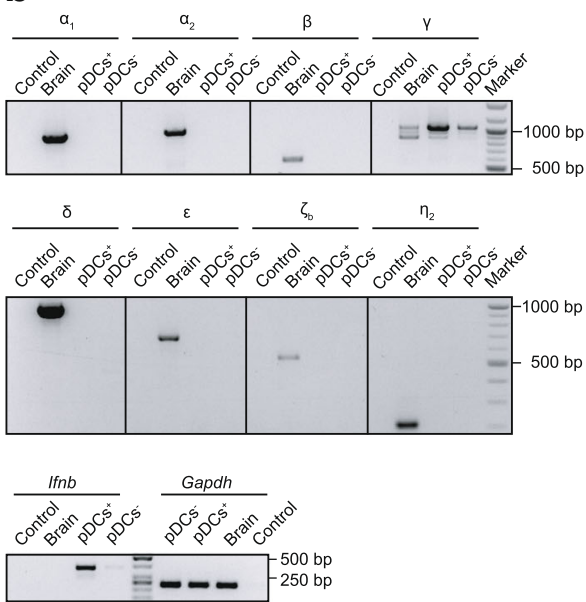

e

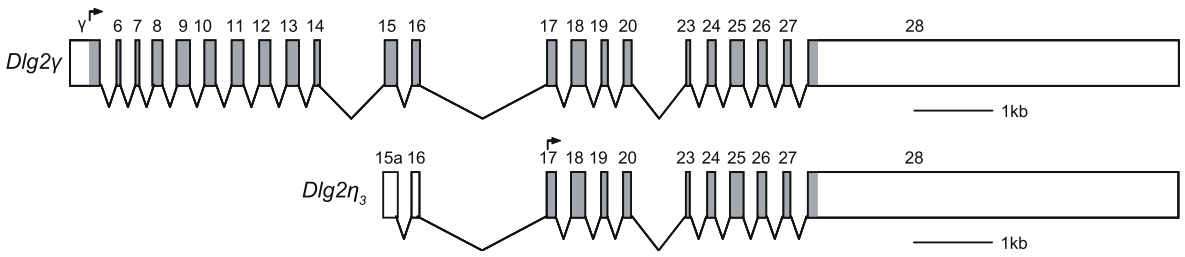

Fig. 2 Analysis of Dlg2 isoforms expressed in IFN $/ \mathrm{NFP}^{+}$-producing pDCs. (a) Gene architecture and alternatively spliced transcripts of the Dlg2 gene. (a, upper graph) Genomic position of Dlg2 gene is presented. Exons are shown as vertical bars and introns as thin horizontal lines. Introns and exons are drawn to scale. Smaller exons (less than 1 point line space) are not to scale. (a, lower graph) Exons are shown as boxes and are drawn to scale. Exons are named or numbered as indicated. Alternative exon-exon-junctions are indicated with connecting lines. Grey boxes show protein coding regions whereas empty boxes represent untranslated mRNA regions. (b) RT-PCR of Dlg2 N-terminal isoforms in IFN $/ Y F P^{+}$ and IFNB/YFP- BM-derived pDCs (upper and middle panel). Flt3L cultures from six pooled IFN $\beta^{\text {mob/mob }}$ mice were stimulated with $\mathrm{CpG}$ for $6 \mathrm{~h}$ and FACS-sorted for $\mathrm{YFP}^{+}\left(\mathrm{pDC}^{+}\right)$and YFP- $\mathrm{pDCs}\left(\mathrm{pDC}^{-}\right)$. Naïve brain from $\mathrm{C} 57 \mathrm{BL} / 6 \mathrm{~N}$ mice was used as positive and not reversely transcribed RNA from YFP ${ }^{+}$pDCs as negative controls (Control). Lower panel shows Gapdh and Ifnb expression in the respective cDNA samples indicating successful stimulation and sorting of pDCs as well as equal template amounts. (c) SH3-GUK linker isoforms of Dlg2 in RT-PCR. SH3-GUK region was amplified using cDNA samples as described above in (b). (d) Restriction analysis of Dlg2 clones generated after 5'-RACE PCR. Empty vector or selected 5'-RACE clones were digested either with EcoRI (left), Hindlll (middle), or with both restriction enzymes (right). Lower panel shows the plasmid maps for the clones shown in the upper panel. (e) Exon-intron structure of the Dlg2 isoforms expressed in pDCs. Exons are shown as boxes and are drawn to scale as shown in A (lower part)

isoforms (Fig. 1b), also higher expression levels were found using primers specific for the $\gamma$-isoform in IFN $\beta$ producing as compared to non-producing pDCs. In brain, two alternatively spliced variants for $D \lg 2 \gamma$, which are derived from alternative inclusion of exon 6 , could be amplified at comparable levels. In pDCs, inclusion of exon 6 appeared relatively more frequent. We went on to define alternative exon usage within the SH3/GKlinker region using primers specific for exons 18 through
23 (Fig. 2c). In RNA preparations from the whole brain, in accordance with the literature [25], alternatively spliced transcripts containing exons 20 through 23 could be detected. We failed, however, to detect transcripts containing either exon 21 or 22 in pDCs. From this RT-PCR analyses we concluded that only the $\gamma$-isoform lacking exons 21 and 22 is expressed in pDCs. These findings emphasized further a pDC specific splicing pattern for Dlg2. Of note, similar expression pattern could be detected in IFN $\beta$-producing 
cDCs (Additional file 4 and data not shown) although expression levels of Dlg2 were around 25-fold less in cDCs as compared to pDCs (Additional file 1). To be also able to identify so far unknown $5^{\prime}$ ends of $D \lg 2$ splice variants in pDCs we performed 5' RACE PCR using a 3 '-primer binding within exon 28 on RNA isolated from IFN $\beta$-producing Flt3L cultured BM-derived pDCs (Fig. 2d). We recovered several clones containing cDNAs for the $\gamma$-isoform but no

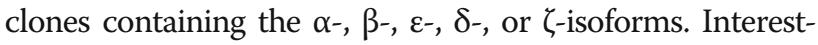
ingly, the majority of the $5^{\prime}$-RACE clones, however, harboured cDNAs from a novel Dlg2 isoform that uses a $5^{\prime}$ transcription start site 28 nucleotides upstream of exon 15 . This novel exon was termed exon 15a. The translational start codon for this isoform is localised in exon 17 and identical to the translational start codon of the $\eta$-isoform identified by our in silico analyses. We termed this novel $D \lg 2$ isoform $D \lg 2 \eta 3$ (Fig. 2e). Taken together, Dlg2 expression in pDCs is restricted to a known $\gamma$ - and a novel $\eta 3-$ isform (MF276899, and MF276900) with skipping of exons 21 and 22. Since these exons, when included, code for the SH3/GK-linker region (Fig. 2) the pDC specific DLG protein isoforms contain a shorter linker region that might mediate specific protein-protein interactions.

\section{Protein expression of DLG2 isoforms in murine pDCs}

Following the analysis of the $D \lg 2$ splicing pattern and the definition of $D l g 2 \gamma$ and $D l g 2 \eta 3$ transcript isoforms in type I IFN-producing pDCs, we further elucidated DLG2 expression at the protein level. Therefore, we performed immunoprecipitation followed by Western blotting for different DLG2 isoforms on pDCs and brain tissue from wildtype (WT) and Dlg2 deficient mice generated before [39] (Fig. 3a, left). Due to the lack of isoform specific antibodies overexpression of recombinant $\gamma^{-}, \eta-$, and $\alpha$-isoforms served as size references (Fig. 3a, right). In protein lysates from BM-derived Flt3L cultured cells from WT mice stimulated for $16 \mathrm{~h}$ with CpG a band of approximately $120 \mathrm{kDa}$ was detectable corresponding well with the band size of the recombinantly expressed $\gamma$-isoform. In brain lysates, at lower levels, expression of at least 2 bands of approximately 110 and $120 \mathrm{kDa}$, the same size of the $\gamma$ - and $\alpha$ isoforms from recombinantly expressed controls, could be found. Both of these bands were not detectable in protein lysates from $D \lg 2$ knock out $\left(D \lg 2^{\triangle E 9 / \Delta E 9}\right)$ mice generated by deleting exon 9 . Of note, in brain and stimulated Flt3L cultures from WT as well and $D \lg 2^{\Delta E 9 / \Delta E 9}$ mice a band of approximately $50 \mathrm{kDa}$ was detectable. This band corresponded in size with the novel $\eta$-isoform expressed in transfected HEK293 cells. Thus, the supposed knock out for $D \lg 2$ harbouring a deletion for a region within the second PDZ domain [39] retains expression of the short $\eta$ isoform of DLG2 lacking all three PDZ domains in brain and Flt3L cultured pDCs (Fig. 3b).
Intracellular localisation of DLG2 $\alpha-, \boldsymbol{\gamma}^{-}$, and $\eta$-isoforms The different DLG2 isoforms and the DLG homo- and orthologues of the MAGUK family have been described to localise differentially to specific intracellular compartments $[33,46]$. To elucidate the preferential localisation of the pDC-specific $\gamma$ - and $\eta$-isoforms we generated expression plasmids encoding GFP-fusion proteins of these DLG2 isoforms. Additionally, the brain-specific $\alpha$-isoform was cloned as a GFP-fusion protein as reference. NIH3T3 cells were transiently transfected with these constructs (Fig. 4). Overexpression of GFP alone resulted in an equal distribution of the fluorescence throughout the cytoplasm and the nucleus (Fig. 4a). The C-terminally GFP-tagged $\alpha$ isoform preferentially localised to the cytoplasmic membrane as identified by costaining with the $\mathrm{Na} / \mathrm{K}$-ATPase serving as a membrane marker (Fig. $4 \mathrm{~b}$ ). The $\alpha$-isoform of DLG2 includes an N-terminal palmitoylation site that enables association with membrane lipids. Thus, the cytoplasmic membrane-associated localisation observed here proves the functionality of this experimental system. Additionally, the $\alpha$-isoform was enriched within an intracytoplasmatic compartment likely representing the Golgi apparatus due to its perinuclear localisation. In contrast, the $\gamma$ - and $\eta$-isoforms showed a distinct localisation when expressed as GFP-fusion proteins. While the $\gamma$-isoform of DLG2 preferentially localised within the cytoplasm and to a lesser extent to the nucleus (Fig. 4c) the $\eta$-isoform was found evenly distributed between the cytoplasmic and nuclear compartments (Fig. 4d). This specific subcellular localisation hints at distinct cellular functions of the respective DLG2 isoforms.

Since increased expression of DLG2 was observed in IFN $\beta$-expressing pDCs and significant levels of DLG2 $\eta$ localized to the nucleus, it can be hypothesized that DLG2 isoforms directly or indirectly regulate the expression of IFN $\beta$ upon CpG stimulation. To test this and due to the lack of availability of cells deficient in the DLG2 $\eta$ isoform, we analyzed the effects of ectopic expression of Dlg2 isoforms on Ifnb promoter activity in a luciferase reporter gene assay. After $\mathrm{CpG}$ stimulation TLR9 signaling leads to a TANK binding kinase 1 (TBK1) induced interferon regulatory factor 7 (IRF7) activation which is a prerequisite for type I interferon expression in pDCs. Overexpression of neither IRF7 nor TBK1 alone were able to significantly activate the Ifnb promoter in NIH3T3 cells. However, co-expression of both molecules increased the Ifnb promoter activity (Fig. 5a) indicating a pDC like TLR9 signal transduction for Ifnb promoter activity in NIH3T3 cells. Using these conditions, we additionally overexpressed different $D l g 2$ isoforms in increasing concentrations. Expression of the $D \lg 2 \eta$ isoform and to lesser extent $D \lg 2 \gamma$ dampen the Ifnb promoter activity whereas overexpression of $D \lg 2 \alpha$ and TPI1 used as an unrelated control did not affect the 


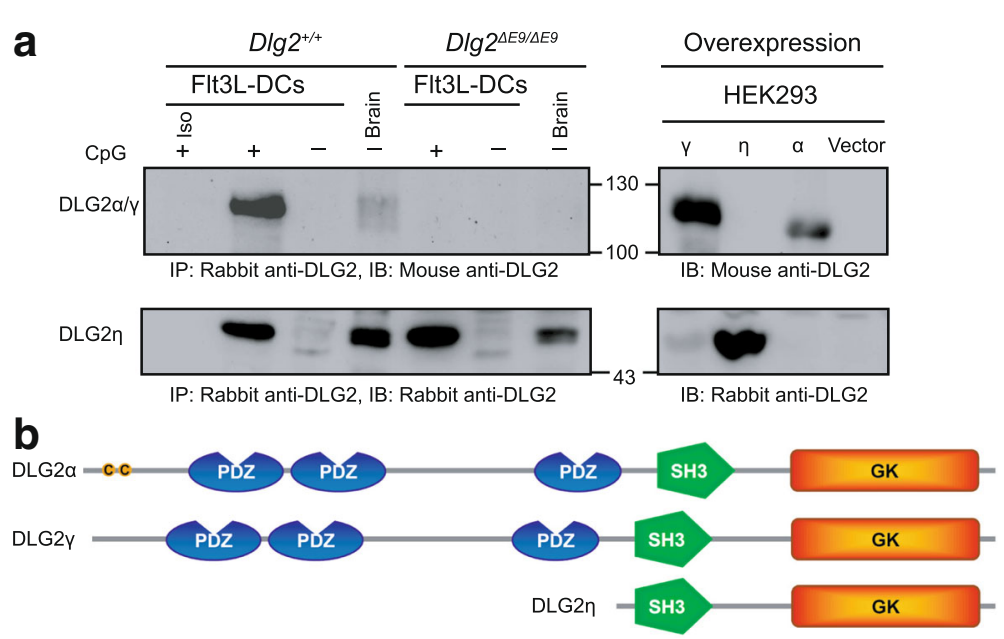

Fig. 3 Protein expression of a novel n-isoform of DLG2 in pDCs. (a) Detection of DLG2 isoforms at protein level in pDCs. DLG2 was immunoprecipitated from BM-derived Flt3L cultured DCs and brain lysates (left panel) from WT or Dlg $2^{\Delta E 9 / \Delta E 9}$ mice. The cells were left untreated or stimulated with $C p G$ for 6 h. Immunoprecipitated DLG2 isoforms were analysed by DLG2 specific immunoblotting (upper panel); Iso: Isotype control antibody. In parallel, recombinant murine DLG2, isoforms (indicated) were expressed in HEK293 cells after transient transfection (right panel). DLG2 isoforms were analysed by immunoblotting as described above. (b) Protein domain organization of the DLG2 $\mathbf{a}-, \gamma^{-}$, and $\eta$-isoform expressed in pDCs. Indicated are the double cysteine-motif of the palmitoylation site within the a-isoform, and the PSD-95/Dlg/ZO-1 (PDZ), Src-homology-3 (SH3), and Guanylate Kinase (GK) domains. Protein length and relative positions of the domains are drawn to scale

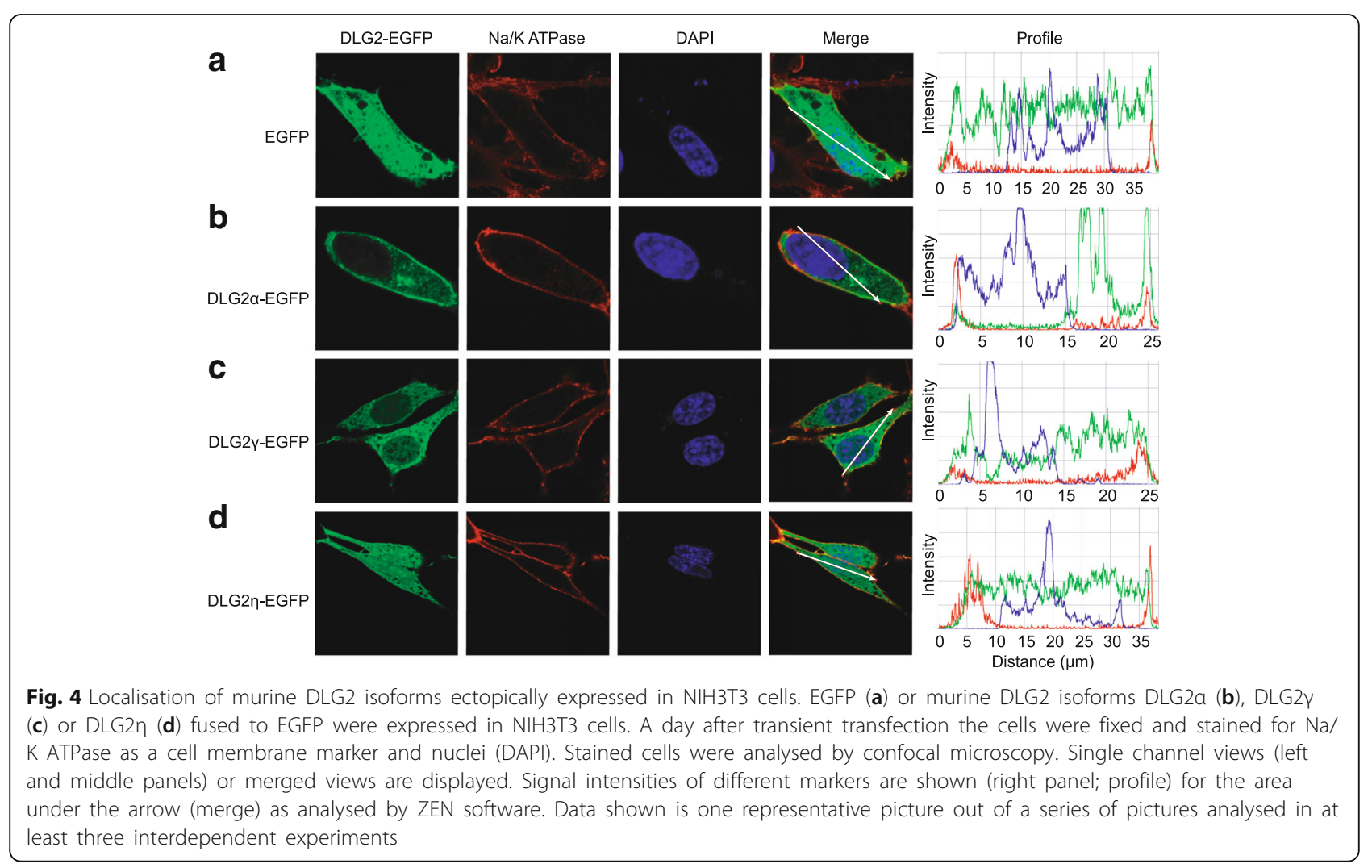




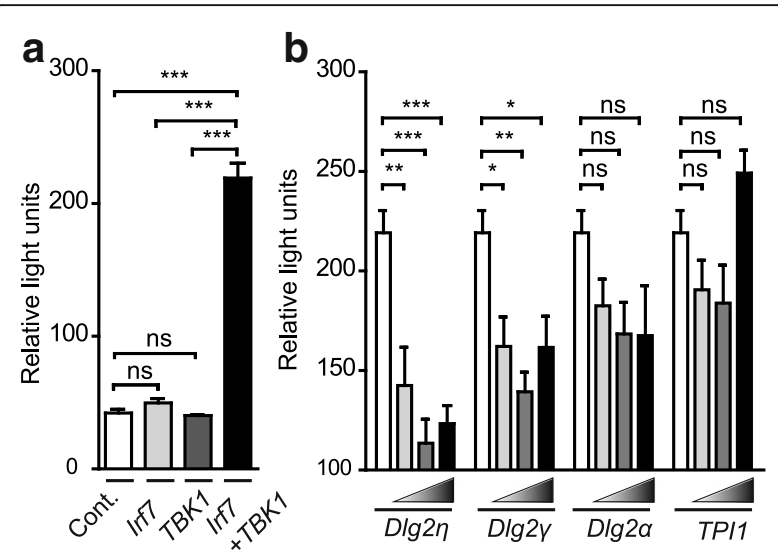

Fig. 5 The effect of ectopic expression of Dlg2 isoforms on Ifnb expression. (a). Effect of IRF7 activation on Ifnb promoter activity. IRF7 or TBK1 were expressed alone or in combination in the presence of Ifnb reporter plasmid. Control (Cont.) shows the basal activity of Ifnb promoter in NIH3T3 cells. (b). Effect of expression of Dlg2 isoforms on Ifnb promoter activity. Increasing amounts of Dlg2 isoforms or TPI gene were transiently transfected along with Irf7, Tbk1 encoding plasmids and an Ifnb reporter vector in NIH3T3 cells. Ifnb promoter activity was measured from cell lysates one day after transfection. Data shown are ratios of relative light unites of Firefly luciferase (under the control of the Ifnb promoter) / Renila luciferase (under the control of the CMV promoter) from one representative experiment performed in quadruplicates out of three independent experiments. Data shown are the means $\pm S E M$. Significance was analyzed by either One-way ANOVA followed by Bonferroni's Multiple Comparison Test (a) or Two-way ANOVA followed by Bonferroni posttests (b). ns: $P>0.05, *: P<0.05, * *: P<0.01, * * *: P<0.001$

Ifnb promoter activity (Fig. 5b). These results are an initial hint that DLG2 $\eta$ and DLG2 $\gamma$ isoforms might function as negative regulators of Ifnb expression.

\section{Discussion}

In a recent transcriptome analysis we found $D \lg 2$ as highly differently expressed in pDCs that produced the antiviral cytokines of the type I IFN family after activation of the pattern recognition receptor TLR9 [36]. We verified the increased expression of Dlg2 in in vitro BMderived as well as ex vivo isolated mouse pDCs after stimulation with the TLR9 ligand CpG. The expression detected on mRNA as well as on protein level correlated with the production of type I IFN in these pDCs. In other cell types tested, such as CDCs and B cells, no increase in Dlg2 levels was observed. This points towards a pDC-specific Dlg2 upregulation after TLR9 stimulation. So far, expression of DLG2 has not been described in this myeloid cell type of the immune system. Rather, as a MAGUK family member, DLG2 is best characterized as a scaffolding protein in the post-synaptic density of neurons. There, DLGs are known to interact with cell adhesion molecules such as $\mathrm{N}$-cadherins that have important roles in structural and functional aspects of synapses [5, 47]. In immune cells also, cell adhesion proteins have vital functions controlling cell migration and homing. It can be envisaged that DLG2 might be involved in $\mathrm{pDC}$ migration and localization within lymphatic as well as peripheral tissues.

Outside the nervous system, DLG2 expression is less well characterized. In expression profiling screens of diverse mouse cell lines and primary immune cell types [34, 35] Dlg2 was detected in splenic red pulp macrophages [48] and more prominently in mast cells [49]. However, activated pDCs were not included in these expression profiling screens. Mast cells are known to be critically involved in the initiation and promotion of airway inflammation and asthma. Interestingly, in a recent genome wide analysis for gene-environment interaction effects on childhood asthma differential methylation and expression of $D L G 2$ was found associated with air pollution exposure [50]. In light of this, further expression and functional analyses of DLG2 in mast cells could reveal important new implications of this MAGUK protein in type 2 driven immunopathologies.

DLG2 has further been implicated in immunopathological mechanisms in a focal ischemic stroke mouse model by exacerbating the cerebral ischemic injury and the induction of pro-inflammatory cytokines and downregulation of anti-inflammatory mediators [51, 52]. Here reduced levels of TNF and IL- 6 but increased amounts of the anti-inflammatory IL-10 were found in the brains of $D \lg 2$ deficient as compared to WT mice after ischemia/reperfusion injury. In this setting iNOS and COX-2 were even downregulated after ischemia induction in the absence of DLG2 while both factors were found increased in the ischemic brains of WT animals [52]. This study linked the known DLG2-mediated neuronal excitotoxicity [53] with the release of iNOS, TNF, and IL-6 presumably by microglia. The exact causal interactions of neurons and microglia and the role of DLG2 therein remain to be elucidated. Based on our findings of DLG2 expression in $\mathrm{pDCs}$, microglia or other brain infiltrating myeloid cells have to be interrogated for a possible direct involvement of DLG2 in pro- and anti-inflammatory cytokine production.

DLG2 can be expressed in multiple isoforms with variable N-terminal domains and alternatively spliced internal exons coding for the SH3-GK linker region [25, 26]. Six Nterminal variants of DLG2 are expressed, albeit at varying levels, in different brain regions [25]. In contrast, our data show that pDCs only express two N-terminal variants, DLG2 $\gamma$ and DLG2 $\eta$. While the shorter DLG2 $\eta$ isoform contains only an SH3 and the GK domain, in the DLG2 $\gamma$ isoform three additional PDZ domains are present at the $\mathrm{N}$-terminus. The DLG2 $\gamma$ isoform neither contains a palmitoylation nor a L27 domain found in the $\alpha$ - and $\beta$-isoforms, respectively. PDZ domains bind specific $\mathrm{C}$-terminal sequences in target proteins $[2,5]$. For the PDZ domains 1 
and 2 of DLG2 inwardly rectifying $\mathrm{K}^{+}$channels and the GluN2B subunit of NMDA receptors have been identified as interaction partners in neurons. The third PDZ domain binds Neuroligins and the Src tyrosin kinase Fyn that regulates synaptic functions of NMDA receptors $[4,54]$. The SH3 domains are commonly known as protein-protein interaction modules in a variety of proteins with widely divergent functions ranging from cell differentiation in embryonic development to cell signalling in immune cells [55]. Finally, the GK domain of MAGUK proteins is catalytically inactive and rather binds phosphorylated proteins as interaction partners, while the proposed orthologue in yeast, the Saccharomyces cerevisiae guanylate kinase (Guk1) catalyses the phosphorylation of GMP to GDP using ATP as the phosphate donor $[2,5,56]$. The SH3-GK linker region is suggested to mediate oligomerization within the MAGUK protein family $[2,5,26,57]$. A future task will be the identification of specific binding partners of DLG2 $\gamma$ and DLG2 $\eta$ in pDCs. A first promising candidate might be Fyn as in pDCs recently this kinase together with another Src family kinase Lyn have been shown to be essential in constitutive and TLR-mediated signaling events [58]. For the DLG2 homologue DLG4 an interaction with nNOS is described. In neurons, it targets this enzyme and thereby formation of NO from L-arginine selectively to the NMDA receptor [2]. It is tempting to speculate that DLG2 in pDCs might be involved in the generation of $\mathrm{NO}$ thereby exhibiting direct immune effector functions.

The specific subcellular localization of alternatively spliced variants of DLG2 may lead to insights towards their respective functions. As a scaffold protein, it might direct signal transduction complexes to different intracellular sites thereby modulating the outcome of signalling cascades. Indeed, we found a preferential localization for DLG2 $\gamma$ within the cytoplasm while DLG2 $\eta$ was detectable also in the nuclear compartment. Interestingly, the MAGUK family protein CASK has been described to be able to translocate into the nucleus and there to regulate neuronal gene expression [59]. While our initial promoter activation experiments suggest a negative regulatory impact of DLG2 on IFN $\beta$ expression after TLR9 activation and its involvement in a negative feedback loop, the precise functions for DLG2 $\eta$ in transcriptional regulation in pDCs and its mechanisms remain to be elucidated.

During our DLG2 expression analyses we detected protein expression of the novel DLG2 $\eta$ isoform in the brain of $D \lg 2^{\triangle E 9 / \Delta E 9}$ mice widely used for the analysis of DLG2dependent biological processes [39]. As whole brain lysates were analysed for residual DLG2 expression in $D \lg 2^{\Delta E 9 / \Delta E 9}$ mice we could not differentiate between neurons, glia, and other cell types of the CNS. It remains to be elucidated if the DLG2 $\eta$ detected is expressed specifically by neurons or other cells of the brain of $D \lg 2^{\triangle E 9 / \Delta E}$ mice. Nevertheless, these observations have to be taken into account in the interpretation of unexpected findings in the $D \lg 2^{\triangle E 9 / \triangle E 9}$ mouse line. For example, although DLG2 is thought to be the only DLG expressed in cerebellar Purkinje neurons, in $D \lg 2^{\triangle E 9 / \Delta E 9}$ mice no defects in the synaptogenesis were observed [39]. Based on these findings it was assumed that the DLG homologues are not essential for synapse development in specific brain regions. Data from our studies indicate that in $D \lg 2^{\triangle E 9 / \Delta E 9}$ mice expression of the $\eta$-isoform is retained in the brain. While the lack of PDZ domains makes it rather unlikely, it cannot be excluded that the short $\eta$-isoform is able to fulfil essential functions in synapse formation. Novel insights regarding the functions of DLG2 in cerebellar Purkinje neurons and also the redundancy of DLG2 and DLG4 in cognitive processes might be gained from complete $D \lg 2$ knock outs to be generated in the future.

\section{Conclusions}

Taken together, here we describe for the first time expression of DLG2 in pDCs that represent the major cellular source of type I interferons in antiviral immune responses. We define the differential expression pattern of a novel splice variant, $D \lg 2 \eta$, in these cells and integrate this information into an updated annotated exon structure for the mouse Dlg2. Analysis of CNS tissue revealed presence of DLG2 $\eta$ protein in previously generated $D \lg 2^{\triangle E 9 / \triangle E 9}$ mice. A yet to be established potential role of this isoform in pDCs and other myeloid cells as well as neurons awaits further clarification.

\section{Additional files}

Additional file 1: Expression of D/g2 in IFN $/$ YFP-producing pDCs and cDCs. (PDF 428 kb)

Additional file 2: Expression of D/g2 in B cells. (PDF $446 \mathrm{~kb}$ )

Additional file 3: Proposed Dlg2 exon names/numbers, length, and location within the genomic sequence and accession numbers of reference sequences they are contained in. (DOCX $44 \mathrm{~kb}$ )

Additional file 4: D/g2 isoforms expressed in IFN $\beta$-producing $\mathrm{pDCs}$ and cDCs. (PDF 560 kb)

\section{Abbreviations}

ATP: Adenosine triphosphate; BM: Bone marrow; CASK: Calcium/calmodulin dependent serine protein kinase; CNS: Central nervous system; COX-

2: Cyclooxygenase-2; CpG: 5'-cytosine-phosphate-guanine-3'; DCs: Dendritic cells; DLG: Discs large homolog; DOTAP: N-[1-(2,3-Dioleoyloxy)propyl]-N,N,Ntrimethylammonium methyl-sulfate; EGFP: Enhanced green fluorescent protein; Flt3L: FMS-like tyrosine kinase 3 ligand; GDP: Guanosine

diphosphate; GK: Guanylate kinase; GMP: Guanosine monophosphate; Guk1: Guanylate kinase 1; IFN: Interferon; IL: Interleukin; iNOS: Inducible nitric oxide synthase; IRF: Interferon regulatory factor; L27: Lin2 Lin7 domain; MAGUK: Membrane-associated guanylate kinase; MOB: Messenger of interferon beta; NMDA: N-methyl-D-aspartate; nNOS: Neuronal nitric oxide synthase; NO: Nitric oxide; PCR: Polymerase chain reaction; pDCs: Plasmacytoid dendritic cells; PDZ: PSD-95/discs large/zona occludens-1 domains; RACE: Rapid amplification of CDNA ends; SH3: Src-homology 3; TBK1: TANK binding kinase 1; TLR: Toll like receptor; TNF: Tumour necrosis factor; WT: Wildtype; YFP: Yellow fluorescent protein 


\section{Acknowledgements}

We thank S. Kropp for excellent technical assistance. We also thank Prof. Seth G. N. Grant (Edinburgh University, Edinburgh, UK) for providing $D \lg 2^{\triangle E 9 / \Delta E 9}$ mice.

\section{Funding}

This work was supported by the Deutsche Forschungsgemeinschaft (SCHE692/3-1, SCHE692/4-1), the Research Commission of the Medical Faculty of the University of Düsseldorf, Germany (30/2016) (to S.S.) and by the Deutsche Forschungsgemeinschaft (FOR 2107, AL 1145/5-2), the IZKF (Alf3/018/16), the DFG EXC 1003, Grant FF-2014-01 Cells in Motion-Cluster of Excellence, Münster, Germany, and the Alzheimer Forschung Initiative e.V. (14835) (to J.A.).

\section{Availability of data and materials}

Additional annotations of the genomic locus of Dlg2 addressing the newly defined splice variants according to the current study were submitted and are available in the GeneBank repository NCBI under the accession codes MF276899 (https://www.ncbi.nlm.nih.gov/nuccore/MF276899) and MF276900 (https://www.ncbi.nlm.nih.gov/nuccore/MF276900). Other datasets generated during and/or analysed during the current study available from the corresponding author on reasonable request.

\section{Authors' contributions}

SA, AH, RJD, HS, SS conceived and designed the experiments; SA, AH, RJD performed the experiments and analysed data; JA, SS supervised the work; $\mathrm{SA}, \mathrm{AH}, \mathrm{HS}$, JA, SS wrote the manuscript. All authors read and approved the final manuscript.

\section{Ethics approval and consent to participate}

This study was carried out in strict accordance with the German act for animal welfare (Tierschutzgesetz) §8. The protocol was approved by the local ethics committee, the board for nature, environment and consumer protection (Landesamt für Natur-, Umwelt-, und Verbraucherschutz - LANUV) of the regional government of Düsseldorf (North Rhine-Westphalia, Germany); Permit number 84-02.05.30.13.034. All efforts were made to minimize suffering.

\section{Consent for publication}

Not applicable

\section{Competing interests}

The authors declare that they have no competing interests.

\section{Publisher's Note}

Springer Nature remains neutral with regard to jurisdictional claims in published maps and institutional affiliations.

\section{Author details \\ 'Institute of Medical Microbiology and Hospital Hygiene, Heinrich, Heine University of Düsseldorf, Universitätsstraße 1, D-40225 Düsseldorf, Germany. ${ }^{2}$ Cluster of Excellence EXC 1003, Cells in Motion, Waldeyerstraße 15, D-48149 Münster, Germany. ${ }^{3}$ Singapore Immunology Network, Agency for Science, Technology, and Research (A*STAR), Singapore 138648, Singapore. ${ }^{4}$ Institute of Virology, Heinrich Heine University of Düsseldorf, Universitätsstraße 1 D-40225 Düsseldorf, Germany. ${ }^{5}$ BMFZ (Biologisch-Medizinisches Forschungszentrum), Heinrich Heine University of Düsseldorf, Universitätsstraße 1, D-40225 Düsseldorf, Germany. ${ }^{6}$ Department of Psychiatry, University of Münster, Albert-Schweitzer-Campus 1, D-48149 Münster, Germany.}

Received: 6 October 2017 Accepted: 1 March 2018

\section{Published online: 12 March 2018}

\section{References}

1. Feng W, Zhang M. Organization and dynamics of PDZ-domain-related supramodules in the postsynaptic density. Nat Rev Neurosci. 2009;10:87-99.

2. Funke L, Dakoji S, Bredt DS. Membrane-associated guanylate kinases regulate adhesion and plasticity at cell junctions. Annu Rev Biochem. 2005; 74:219-45.

3. Grant SG. A general basis for cognition in the evolution of synapse signaling complexes. Cold Spring Harb Symp Quant Biol. 2009;74:249-57.
4. Won S, Levy JM, Nicoll RA, Roche KW. MAGUKs: multifaceted synaptic organizers. Curr Opin Neurobiol. 2017:43:94-101.

5. Zhu J, Shang Y, Zhang M. Mechanistic basis of MAGUK-organized complexes in synaptic development and signalling. Nat Rev Neurosci. 2016;17:209-23.

6. Elias GM, Nicoll RA. Synaptic trafficking of glutamate receptors by MAGUK scaffolding proteins. Trends Cell Biol. 2007;17:343-52.

7. Ryan TJ, Grant SG. The origin and evolution of synapses. Nat Rev Neurosci. 2009;10:701-12

8. Nithianantharajah J, Komiyama NH, McKechanie A, Johnstone M, Blackwood DH, St Clair D, Emes RD, van de Lagemaat LN, Saksida LM, Bussey TJ, et al. Synaptic scaffold evolution generated components of vertebrate cognitive complexity. Nat Neurosci. 2013;16:16-24.

9. Su WH, Mruk DD, Wong EW, Lui WY, Cheng CY. Polarity protein complex scribble/Lgl/Dlg and epithelial cell barriers. Adv Exp Med Biol. 2012;763:149-70.

10. Stohr $\mathrm{H}$, Weber $\mathrm{BH}$. Cloning and characterization of the human retinaspecific gene MPP4, a novel member of the p55 subfamily of MAGUK proteins. Genomics. 2001;74:377-84.

11. Inagaki H, Tanaka K, Takada M, Maeda S, Ichihara S, Saito T. Spatial distribution of mDLG6 mRNA in embryonic and adult mouse brain. Cell Biol Int. 2002;26: 635-40

12. Grant SG, Marshall MC, Page KL, Cumiskey MA, Armstrong JD. Synapse proteomics of multiprotein complexes: en route from genes to nervous system diseases. Hum Mol Genet 2005;14 Spec. 2:R225-34.

13. Fernandez E, Collins MO, Uren RT, Kopanitsa MV, Komiyama NH, Croning MD, Zografos L, Armstrong JD, Choudhary JS, Grant SG. Targeted tandem affinity purification of PSD-95 recovers core postsynaptic complexes and schizophrenia susceptibility proteins. Mol Syst Biol. 2009:5:269.

14. Xu B, Roos JL, Levy S, van Rensburg EJ, Gogos JA, Karayiorgou M. Strong association of de novo copy number mutations with sporadic schizophrenia. Nat Genet. 2008:40:880-5

15. Walsh T, McClellan JM, McCarthy SE, Addington AM, Pierce SB, Cooper GM, Nord AS, Kusenda M, Malhotra D, Bhandari A, et al. Rare structural variants disrupt multiple genes in neurodevelopmental pathways in schizophrenia. Science. 2008:320:539-43.

16. International Schizophrenia. C. Rare chromosomal deletions and duplications increase risk of schizophrenia. Nature. 2008;455:237-41.

17. Kirov G, Pocklington AJ, Holmans P, Ivanov D, Ikeda M, Ruderfer D, Moran J, Chambert K, Toncheva D, Georgieva L, et al. De novo CNV analysis implicates specific abnormalities of postsynaptic signalling complexes in the pathogenesis of schizophrenia. Mol Psychiatry. 2012;17:142-53.

18. Clinton SM, Meador-Woodruff JH. Abnormalities of the NMDA receptor and associated intracellular molecules in the thalamus in schizophrenia and bipolar disorder. Neuropsychopharmacology. 2004;29:1353-62.

19. Toyooka K, Iritani S, Makifuchi T, Shirakawa O, Kitamura N, Maeda K, Nakamura R, Niizato K, Watanabe M, Kakita A, et al. Selective reduction of a PDZ protein, SAP-97, in the prefrontal cortex of patients with chronic schizophrenia. J Neurochem. 2002:83:797-806.

20. Tarpey P, Parnau J, Blow M, Woffendin H, Bignell G, Cox C, Cox J, Davies H, Edkins S, Holden S, et al. Mutations in the DLG3 gene cause nonsyndromic X-linked mental retardation. Am J Hum Genet. 2004;75:318-24.

21. Jamain S, Quach H, Betancur C, Rastam M, Colineaux C, Gillberg IC, Soderstrom H, Giros B, Leboyer M, Gillberg C, et al. Mutations of the X-linked genes encoding neuroligins NLGN3 and NLGN4 are associated with autism. Nat Genet. 2003;34: 27-9.

22. Chen SP, Fuh JL, Chung MY, Lin YC, Liao YC, Wang YF, Hsu CL, Yang UC, Lin MW, Chiou JJ, et al. Genome-wide association study identifies novel susceptibility loci for migraine in Han Chinese resided in Taiwan. Cephalalgia. 2017; doi:https://doi.org/10.1177/0333102417695105

23. Reggiani C, Coppens S, Sekhara T, Dimov I, Pichon B, Lufin N, Addor MC, Belligni EF, Digilio MC, Faletra F, et al. Novel promoters and coding first exons in DLG2 linked to developmental disorders and intellectual disability. Genome Med. 2017;9:67.

24. Winkler D, Daher F, Wustefeld L, Hammerschmidt K, Poggi G, Seelbach A, Krueger-Burg D, Vafadari B, Ronnenberg A, Liu Y, et al. Hypersocial behavior and biological redundancy in mice with reduced expression of PSD95 or PSD93. Behav Brain Res. 2017; doi:https://doi.org/10.1016/j.bbr.2017.02.011.

25. Kruger JM, Favaro PD, Liu M, Kitlinska A, Huang X, Raabe M, Akad DS, Liu Y, Urlaub $\mathrm{H}$, Dong $\mathrm{Y}$, et al. Differential roles of postsynaptic density-93 isoforms in regulating synaptic transmission. J Neurosci. 2013;33:15504-17.

26. Zheng CY, Seabold GK, Horak M, Petralia RS. MAGUKs, synaptic development, and synaptic plasticity. Neuroscientist. 2011;17:493-512. 
27. Craven SE, Bredt DS. PDZ proteins organize synaptic signaling pathways. Cell. 1998:93:495-8.

28. Hillier BJ, Christopherson KS, Prehoda KE, Bredt DS, Lim WA. Unexpected modes of PDZ domain scaffolding revealed by structure of nNOSsyntrophin complex. Science. 1999;284:812-5.

29. Sheng M. PDZs and receptor/channel clustering: rounding up the latest suspects. Neuron. 1996;17:575-8.

30. Carlisle HJ, Fink AE, Grant SG, O'Dell TJ. Opposing effects of PSD-93 and PSD-95 on long-term potentiation and spike timing-dependent plasticity. J Physiol. 2008;586:5885-900.

31. Parker MJ, Zhao S, Bredt DS, Sanes JR, Feng G. PSD93 regulates synaptic stability at neuronal cholinergic synapses. J Neurosci. 2004;24:378-88.

32. Kim E, Cho KO, Rothschild A, Sheng M. Heteromultimerization and NMDA receptor-clustering activity of Chapsyn-110, a member of the PSD-95 family of proteins. Neuron. 1996;17:103-13.

33. Rumbaugh G, Sia GM, Garner CC, Huganir RL. Synapse-associated protein-97 isoform-specific regulation of surface AMPA receptors and synaptic function in cultured neurons. J Neurosci. 2003;23:4567-76.

34. Heng TS, Painter MW. Immunological genome project C. The immunological genome project: networks of gene expression in immune cells. Nat Immunol. 2008;:1091-4

35. Wu C, Orozco C, Boyer J, Leglise M, Goodale J, Batalov S, Hodge CL, Haase J, Janes J, Huss JW 3rd, et al. BioGPS: an extensible and customizable portal for querying and organizing gene annotation resources. Genome Biol. 2009; 10:R130.

36. Bauer J, Dress RJ, Schulze A, Dresing P, Ali S, Deenen R, Alferink J, Scheu S. Cutting edge: IFN-beta expression in the spleen is restricted to a subpopulation of Plasmacytoid dendritic cells exhibiting a specific immune modulatory transcriptome signature. J Immunol. 2016;196:4447-51.

37. Gilliet M, Cao W, Liu YJ. Plasmacytoid dendritic cells: sensing nucleic acids in viral infection and autoimmune diseases. Nat Rev Immunol. 2008;8:594-606.

38. Reizis B, Bunin A, Ghosh HS, Lewis KL, Sisirak V. Plasmacytoid dendritic cells: recent progress and open questions. Annu Rev Immunol. 2011;29:163-83.

39. McGee AW, Topinka JR, Hashimoto K, Petralia RS, Kakizawa S, Kauer FW, Aguilera-Moreno A, Wenthold RJ, Kano M, Bredt DS. PSD-93 knock-out mice reveal that neuronal MAGUKs are not required for development or function of parallel fiber synapses in cerebellum. J Neurosci. 2001;21:3085-91.

40. Scheu S, Dresing P, Locksley RM. Visualization of IFNbeta production by plasmacytoid versus conventional dendritic cells under specific stimulation conditions in vivo. Proc Natl Acad Sci U S A. 2008;105:20416-21.

41. Ehrhardt C, Schmolke M, Matzke A, Knoblauch A, Will C, Wixler V, Ludwig S. Polyethylenimine, a cost-effective transfection reagent. Signal Transduction. 2006;6:179-84

42. Boehm V, Haberman N, Ottens F, Ule J, Gehring NH. 3' UTR length and messenger ribonucleoprotein composition determine endocleavage efficiencies at termination codons. Cell Rep. 2014;9:555-68.

43. Ali S, Huber M, Kollewe C, Bischoff SC, Falk W, Martin MU. IL-1 receptor accessory protein is essential for IL-33-induced activation of T lymphocytes and mast cells. Proc Natl Acad Sci U S A. 2007:104:18660-5.

44. Buchta CM, Bishop GA. Toll-like receptors and B cells: functions and mechanisms. Immunol Res. 2014;59:12-22.

45. Marasco E, Farroni C, Cascioli S, Marcellini V, Scarsella M, Giorda E, Piano Mortari E, Leonardi L, Scarselli A, Valentini D, et al. B-cell activation with CD40L or CpG measures the function of B-cell subsets and identifies specific defects in immunodeficient patients. Eur J Immunol. 2017;47:131-43.

46. Roberts S, Delury C, Marsh E. The PDZ protein discs-large (DLG): the 'Jekyll and Hyde' of the epithelial polarity proteins. FEBS J. 2012;279:3549-58.

47. Dalva MB, McClelland AC, Kayser MS. Cell adhesion molecules: signalling functions at the synapse. Nat Rev Neurosci. 2007:8:206-20.

48. Immunological Genome Project. Immunological genome project consortium, Cambridge. 2017. http://www.immGen.org. Accessed 23 Sept 2017.

49. BioGPS. The Scripps institute, La Jolla. 2017. http://biogps.org/\#goto= genereport\&id=23859. Accessed 23 Sept 2017

50. Gref A, Merid SK, Gruzieva O, Ballereau S, Becker A, Bellander T, Bergstrom A, Bosse $Y$, Bottai M, Chan-Yeung M, et al. Genome-wide interaction analysis of air pollution exposure and childhood asthma with functional follow-up. Am J Respir Crit Care Med. 2017;195:1373-83.

51. Zhang M, Li Q, Chen L, Li J, Zhang X, Chen X, Zhang Q, Shao Y, Xu Y. PSD93 deletion inhibits Fyn-mediated phosphorylation of NR2B and protects against focal cerebral ischemia. Neurobiol Dis. 2014;68:104-11.
52. Zhang Q, Cheng H, Rong R, Yang H, Ji Q, Li Q, Rong L, Hu G, Xu Y. The effect of PSD-93 deficiency on the expression of early inflammatory cytokines induced by ischemic brain injury. Cell Biochem Biophys. 2015;73: 695-700.

53. Xu Y, Zhang B, Hua Z, Johns RA, Bredt DS, Tao YX. Targeted disruption of PSD-93 gene reduces platelet-activating factor-induced neurotoxicity in cultured cortical neurons. Exp Neurol. 2004;189:16-24.

54. Sato $Y$, Tao YX, Su Q, Johns RA. Post-synaptic density-93 mediates tyrosinephosphorylation of the N-methyl-D-aspartate receptors. Neuroscience. 2008; 153:700-8.

55. Kuriyan J, Cowburn D. Modular peptide recognition domains in eukaryotic signaling. Annu Rev Biophys Biomol Struct. 1997;26:259-88.

56. Li Y, Zhang Y, Yan H. Kinetic and thermodynamic characterizations of yeast guanylate kinase. J Biol Chem. 1996;271:28038-44.

57. Alie $\mathrm{A}$, Manuel M. The backbone of the post-synaptic density originated in a unicellular ancestor of choanoflagellates and metazoans. BMC Evol Biol. 2010;10:34.

58. Dallari S, Macal M, Loureiro ME, Jo Y, Swanson L, Hesser C, Ghosh P, Zuniga El. Src family kinases Fyn and Lyn are constitutively activated and mediate plasmacytoid dendritic cell responses. Nat Commun. 2017;8:14830.

59. Hsueh YP, Wang TF, Yang FC, Sheng M. Nuclear translocation and transcription regulation by the membrane-associated guanylate kinase CASK/LIN-2. Nature. 2000;404:298-302.

\section{Submit your next manuscript to BioMed Central and we will help you at every step:}

- We accept pre-submission inquiries

- Our selector tool helps you to find the most relevant journal

- We provide round the clock customer support

- Convenient online submission

- Thorough peer review

- Inclusion in PubMed and all major indexing services

- Maximum visibility for your research

Submit your manuscript at www.biomedcentral.com/submit
C Biomed Central 